\title{
Analysis of BMP4 (rs121912765) polymorphism in Iranian women with history of recurrent spontaneous abortion: A case-control study
}

\author{
MANOUCHEHR MAZDAPOUR, MAHMOOD DEHGHANI ASHKEZARI and SEYED MORTEZA SEIFATI
}

Medical Biotechnology Research Center, Ashkezar Branch, Islamic Azad University, Ashkezar, Yazd 2362542566, Iran

Received May 14, 2018; Accepted July 23, 2018

DOI: $10.3892 /$ br.2018.1170

\begin{abstract}
Recurrent spontaneous abortion (RSA) defines as the consecutive loss of at least two pregnancies prior to the 20th week of gestation. A qualitative diagnosis of infertility can only be performed by focusing on female and male physical abnormalities, endocrine irregularities and genetic conditions. The aim of the present study was to evaluate the association between a common polymorphism of bone morphogenetic protein 4 (BMP4) $(\mathrm{rs} 121912765 ; 278 \mathrm{~A}>\mathrm{G})$ with female infertility. At present there is a lack of data on the relevance of $B M P 4$ polymorphism to spontaneous abortion among Iranian subjects. In the present case-control study, the BMP4 (rs121912765) polymorphism was investigated in 70 infertile women and 100 healthy subjects from Iran by polymerase chain reaction-restriction fragment length polymorphism analysis. Odds ratios (ORs) and 95\% confidence intervals (CIs) for the association between BMP4 (rs121912765) polymorphism and risk of recurrent abortion risk in Iranian women were determined using binary logistic regression, and the genotype and allele frequencies were compared using the $\chi^{2}$ test. Results indicated significant association between the rs121912765 polymorphism and recurrent spontaneous abortion. The $\chi^{2}$ test indicated that the allele frequencies differed $(\mathrm{OR}=0.071,95 \% \mathrm{CI}=0.022-0.181 ; \mathrm{P}<0.0001)$, with the A allele appearing more prevalent in the case samples. Therefore, this polymorphism may be a useful genetic marker for diagnosing female infertility in the context of RSA. The study of such a polymorphism can provide an important basis for targeting interventions and prevention in high-risk individuals. Therefore, further studies are necessary to establish the association of BMP4 (rs121912765) polymorphism in larger and more diverse populations.
\end{abstract}

Correspondence to: Dr Mahmood Dehghani Ashkezari, Medical Biotechnology Research Center, Ashkezar Branch, Islamic Azad University, 1 Daneshgah Street, Ashkezar, Yazd 2362542566, Iran E-mail: mohmood.dehghany.ashkezary@gmail.com

Key words: recurrent spontaneous abortion, bone morphogenetic protein 4, polymorphism, infertility

\section{Introduction}

Recurrent miscarriage is among the most common complications of pregnancy. Approximately, 1 in every 300 women experiences recurrent abortion (1). Recurrent spontaneous abortion (RSA) is defined as two or more consecutive miscarriages before the 20th week of gestation (1). Reportedly 2-4\% of RSA cases are associated with genetic factors (2). In particular, gene polymorphism has been associated with male and female infertility and may serve a central role in RSA $(3,4)$. Several genes [e.g. insulin receptor substrate 2 (IRS2), progesterone receptor $(P G R)$, bone morphogenetic protein $4(B M P 4)$ ] have been implicated in female infertility; for instance IRS2 defects have been associated with reduced numbers of follicles (5) and $P g r$ aberrancies in mice with defects in ovulation, implantation, sexual behavior and mammary gland development (6).

$B M P 4$ is considered among the most important genes indicated to affect fertility (7). BMP4 is a member of the BMP family, and its role in fertility has previously been documented. It particularly appears to affect female fertility by encoding a secreted ligand of the transforming growth factor- $\beta$ (TGFB) family, which activates the SMAD family transcription factors to regulate gene expression $(7,8)$. Mutations in this gene have been associated with several disorders and may have potent effects on developing oocytes and therefore female infertility $(9,10)$. The $B M P 4$ gene contains four exons, spans $\sim 7 \mathrm{~kb}$, and is located at chromosome region 14q22-q23. The first two exons are noncoding, while the coding exons encode a protein comprised of 408 amino acids, which form a TGFB1 propeptide and a TGFB domain that make up an active dimer $(11,12)$. $B M P 4$, as a regulatory and signaling molecule, is among the growth and differentiation factors that are found in primary embryonic development (12). The dorsal region of the notochord secretes BMP4, and the signaling molecule serves a central role in early differentiation of the embryo and organizes the dorsal-ventral axis (13). BMP4 has further important roles during development, including in tooth development, limb formation and bone induction.

$B M P 4$ is a paracrine growth factor, and in conjunction with $B M P 7$, may function to regulate early ovarian follicle development and primordial-to-primary follicle transition. Notably, the available evidence indicates that BMP4 has a critical role in the survival and prevention of apoptosis in oocytes (7); thus with regard to its roles in fertility, these likely manifest 
in oocyte maintenance. The aim of the present case-control study was to estimate allele and genotype frequencies of BMP4 (rs121912765) polymorphism (278A>G; Glu93Gly) in order to investigate the potential association between this polymorphism and spontaneous abortion in Iranian women. To date, there has been a lack of data to show the relevance of this ethnic population to BMP4 polymorphism and spontaneous abortion. The results of this study were therefore hoped to contribute to understanding of the genetic factors associated with recurrent abortion risk in Iranian women.

\section{Materials and methods}

Patients and samples. This case-control study was performed on 70 women with a history of RSA and 100 healthy women with a history of at least one live birth and no history of infertility or abortion as controls The mean age of the study population was $26 \pm 5$ years old. The patients' blood samples were collected at Tehran Woman General Hospital (Mirza Kochak Khan), Tehran, Iran, between January 2015 and October 2016. The patients were also examined for known factors affecting RSA, including for anatomical abnormalities (by clinical examination and imaging methods), immunological factors [immunoglobulin (Ig)G and IgM phospholipid levels], endocrine factors (serum follicle-stimulating hormone, luteinizing hormone and testosterone), and Factor V Leiden and prothrombin mutations (by reverse dot-blot analysis), and were indicated to be normal with regard to these factors. All patients and their partners had a normal karyotype. The control group comprised healthy women with no history of abortion and a history of at least one live birth. All subjects were informed of the study protocol in written and verbal form and provided written informed consent. The study was approved by the Research Committee at Islamic Azad University, Yazd, Iran (IR.IAU.YAZD.REC.1396, 15).

Polymerase chain reaction (PCR)-restriction fragment length polymorphism (RFLP) assay. Genomic DNA from venous blood samples (5 $\mathrm{ml})$ was isolated using a DNA Extraction kit (Qiagen GmbH, Hilden, Germany) according to the manufacturer's instructions. The DNA was quantified with a NanoDrop 1000 Spectrophotometer (Thermo Fisher Scientific, Inc., Waltham, MA, USA) and a concentration of $50 \mathrm{ng} / \mu \mathrm{l}$ was prepared in tubes. Primers for BMP4 were designed using Gene Runner software (version 6.0; http://www.generunner.net/). The sequences of the primers were forward, 5'-AAAGTCGCCGA GATTCAGGG-3' and reverse, 5'-TTTCACTGGTCCCTGGG ATG-3'. The PCR cycling conditions were an initial denaturation step for $5 \mathrm{~min}$ at $94^{\circ} \mathrm{C}$, followed by 35 cycles of $40 \mathrm{sec}$ at $94^{\circ} \mathrm{C}, 40 \mathrm{sec}$ at $61^{\circ} \mathrm{C}$ and $40 \mathrm{sec}$ at $72^{\circ} \mathrm{C}$, and a final extension step at $72^{\circ} \mathrm{C}$ for $5 \mathrm{~min}$. For the reaction, $2 \mu \mathrm{l}$ forward primer, $2 \mu \mathrm{l}$ reverse primer, $5.5 \mu 1$ sterilized distilled water, $3 \mu 1$ DNA $(50 \mathrm{ng} / \mathrm{ml})$ and master mix $[20 \mathrm{mM}$ Tris $-\mathrm{HCl} \mathrm{pH}=8.6$, $50 \mathrm{mM} \mathrm{KCl}, 0.5 \mu \mathrm{l}$ dNTPs $(10 \mathrm{mM}), 0.75 \mu 1 \mathrm{MgCl} 2(50 \mathrm{mM})$ and $0.3 \mu \mathrm{l} 5 \mathrm{U} / \mu \mathrm{l}$ Taq DNA polymerase (CinnaGen Co., Tehran, Iran)] were used.

BMP4 (rs121912765) polymorphism genotyping was performed based on the restriction fragment length polymorphism method. The MnlI restriction enzyme was used and the expected

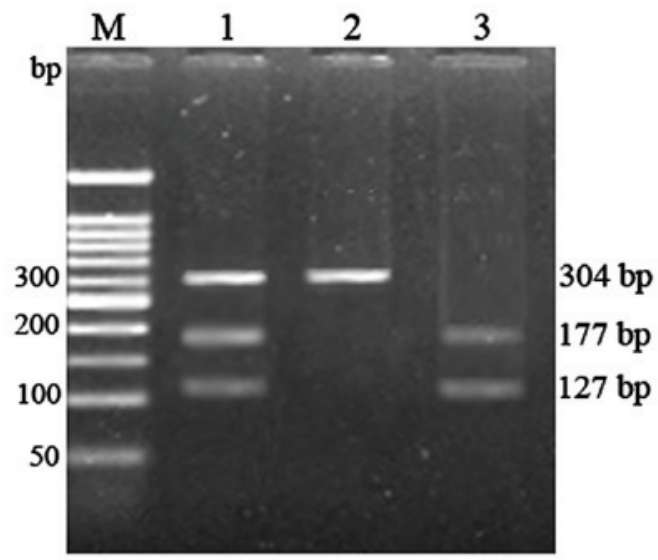

Figure 1. Polymerase chain reaction-restriction fragment length polymorphism assay of bone morphogenetic protein 4 (rs121912765) polymorphism using MnlI restriction enzyme digestion. Lane M shows the 50-bp DNA marker on $3 \%$ agarose gel; lane 1 shows the heterozygous $(A / G)$ digest products; lane 2 shows the dominant homozygous (A/A) digest product; and lane 3 shows the recessive homozygous $(\mathrm{G} / \mathrm{G})$ digest products.

fragments following digestion with restriction enzyme were one fragment of $304 \mathrm{bp}$ for the dominant homozygous (A/A) genotype, two fragments of 127 and $177 \mathrm{bp}$ for the recessive homozygous (G/G) genotype, and three fragments of 304, 177 and $127 \mathrm{bp}$ for the heterozygous (A/G) genotype). The PCR products following restriction digest were separated by electrophoresis on 3\% agarose gel. A 50 bp DNA marker was used and the bands were visualized on a gel documentation system using Gel Red dye. Fig. 1 depicts a representative gel of the expected fragments.

Statistical analysis. Statistical analysis was performed using SPSS software (version 18.0; SPSS Inc., Chicago, IL, USA). The odds ratios (ORs) and 95\% confidence intervals (CIs) for the association between BMP4 (rs121912765) polymorphism and risk of recurrent abortion risk were determined using binary logistic regression, and the genotype and allele frequencies were compared using the $\chi^{2}$ test. $\mathrm{P}<0.05$ was considered to indicate statistical significance.

\section{Results}

Frequencies of the BMP4 (rs121912765) polymorphism. In the present case-control study, case and control samples were genotyped and analyzed for the BMP4 (rs121912765) polymorphism. The allele and genotype frequencies of the BMP4 (rs121912765) polymorphism are presented in Tables I and II, respectively.

Allele frequencies of BMP4 (rs121912765) polymorphism. The polymorphism A and G allele frequencies were 97.1 and $2.9 \%$ among the RSA patients, and 69.0 and $31.0 \%$ among the normal controls. The $\chi^{2}$ test indicated that the allele frequencies differed (OR=0.07, 95\% $\mathrm{CI}=0.022-0.181 ; \mathrm{P}<0.0001)$, with the A allele appearing more prevalent in the case samples (Table I). Thus, the case group exhibited an increased frequency of the BMP4 polymorphism A allele, as compared with that in the controls, and it appeared this polymorphism may have conferred a slightly increased risk of developing RSA in the Iranian study population. 
Table I. Allele frequencies of BMP4 (rs121912765) polymorphism in cases of recurrent spontaneous abortion and controls.

\begin{tabular}{|c|c|c|c|c|}
\hline Allele & Controls, n (\%) & Cases, n (\%) & Odds ratio (95\% confidence interval) & P-value \\
\hline A & $138(69.0)$ & $136(97.1)$ & - & 1 (Ref.) \\
\hline G & $62(31.0)$ & $4(2.9)$ & $0.071(0.022-0.181)$ & \\
\hline$<0.0001$ & & & & \\
\hline
\end{tabular}

$B M P 4$, bone morphogenetic protein 4 .

Table II. Genotype frequencies of BMP4 (rs121912765) polymorphism in cases of recurrent spontaneous abortion and controls.

\begin{tabular}{|c|c|c|c|c|}
\hline Genotype & Controls, n (\%) & Cases, n (\%) & Odds ratio ( $95 \%$ confidence interval) & P-value \\
\hline AA & $48(48.0)$ & $67(95.7)$ & 1 (Ref.) & - \\
\hline $\mathrm{AG}$ & $42(42.0)$ & $2(2.8)$ & $0.034(0.008-0.148)$ & \\
\hline \multicolumn{5}{|l|}{$<0.0001$} \\
\hline GG & $10(10.0)$ & $1(1.5)$ & $0.072(0.009-0.579)$ & 0.013 \\
\hline
\end{tabular}

BMP4, bone morphogenetic protein 4 .

Genotype frequencies of BMP4 (rs121912765) polymorphism. In the case and control subjects, the AA genotype frequency of BMP4 (rs121912765) was 95.7 and $48.0 \%$, the AG genotype frequency was 2.8 and $42.0 \%$, and the GG genotype frequency was 1.5 and $10.0 \%$, respectively. The genotype frequencies were determined to differ significantly between the RSA patients and normal controls $(\mathrm{OR}=0.034$, 95\% CI=0.008-0.148; $\mathrm{P}<0.0001)$, with the AG genotype appearing more prevalent in controls, and AA more prevalent in case samples (Table II).

\section{Discussion}

RSA is a complex process involving various genes and nongenetic factors (14). The gene mutations and polymorphisms in the BMP gene family, particularly in BMP4, have been associated with different diseases and disorders including infertility (15). In fact infertility is among the most important of disorders to be linked with this family of genes in humans. The present study to the best of our knowledge is the first to report that BMP4 (rs121912765) polymorphism may have an effect on RSA in Iranian women; however, further studies are necessary to confirm the association in other populations.

The present research is to the best of our knowledge the first to report that the BMP4 (rs121912765) polymorphism may have effect on RSA occurrence; however, further studies are necessary to confirm the association in other populations. Nevertheless, an increased frequency of the A allele among RSA patients compared with in controls suggested an association between the BMP4 (rs121912765) polymorphism and fertility. In this study, the AA genotype frequency of the polymorphism was 95.7 and $48.0 \%$, the AG genotype frequency was 2.8 and $42.0 \%$, and the GG genotype frequency was 1.5 and $10.0 \%$ in cases and controls, respectively. The results suggested that the AA genotype may be an important genetic risk factor of female infertility in Iran.

The majority of the literature reports that the BMP gene family serves an important role in female fertility. A study by Lawson et al (16) demonstrated in mice that Bmp 4 was required for the generation of germ cells in the embryo; Bmp 4 was expressed in the extraembryonic mesoderm, but not in primordial germ cells (PGCs), indicating that it is Bmp4 expression in the extraembryonic ectoderm that regulates the formation of allantois and primordial germ cell precursors, and the size of the PGC population. Thus Bmp4 expression appeared to have a key role in fertility. In another study, Ying and Zhao (8) reported that $B M P 2$ and particularly BMP4 served a key role in female fertility, being the key regulatory genes that guided oocyte development. Further work by Galloway et al (17) revealed that the BMP family genes increased the ovulation rate and potentially other factors related to fertility in a dosage-sensitive manner. Such previous studies have suggested the BMP family (particularly the BMP2, -4 , and -15 genes) to be obviously involved in the development of oocytes and, therefore, infertility $(8,15-17)$. Based on this previously reported function of the BMP4 gene, the current study elucidated a possible association between polymorphism of the BMP4 gene and female infertility in the context of RSA. The present findings overall support that the BMP4 pathway may serve a key role in female fertility. In particular, the BMP4 (rs121912765) polymorphism may be a genetic risk factor for spontaneous abortion in Iranian women. Further study on this topic should be performed to provide novel data on the role of other polymorphisms of this gene in female infertility in other populations.

With the increasing recognition of genetic-environmental interactions in the etiology of RSA and the advances in genetics technology, it is necessary to include genetic information in 
epidemiological studies to identify how certain polymorphic traits are associated with several phenotypic traits. However, knowledge about the genetic factors determining RSA in the general population remains limited. Therefore, the indicated association of the BMP4 (rs121912765) polymorphism may be population specific and influenced by environmental factors.

\section{Acknowledgements}

The current article was from the $\mathrm{PhD}$ thesis of Dr Manouchehr Mazdapour from the Medical Biotechnology Research Center, Ashkezar Branch, of Islamic Azad University (Yazd, Iran).

\section{Funding}

The present study funded by the Medical Biotechnology Research Center, Ashkezar Branch, of Islamic Azad University (Yazd, Iran; grant no. 23624).

\section{Availability of data and materials}

The datasets used and/or analyzed during the current study are available from the corresponding author on reasonable request.

\section{Authors' contributions}

MM contributed to study conception and design, and to acquisition and interpretation of data. MDA and SMS were involved in drafting of the manuscript and revising it for intellectual content, and gave final approval of the version to be published.

\section{Ethics approval and consent to participate}

The study was approved by the Research Committee at Islamic Azad University, Yazd, Iran (IR.IAU.YAZD.REC.1396, 15) and informed consent for participation was obtained from all participants following a debrief of the study protocol.

\section{Consent for publication}

Informed consent for the publication of any associated data was obtained from all participants on the basis of anonymization.

\section{Competing interests}

The authors declare that they have no competing interests.

\section{References}

1. Doubilet PM, Benson CB, Bourne T, Blaivas M, Barnhart KT, Benacerraf BR, Brown DL, Filly RA, Fox JC, Goldstein SR, et al; Society of Radiologists in Ultrasound Multispecialty Panel on Early First Trimester Diagnosis of Miscarriage and Exclusion of a Viable Intrauterine Pregnancy: Diagnostic criteria for nonviable pregnancy early in the first trimester. N Engl J Med 369: 1443-1451, 2013.

2. Vitzthum VJ, Spielvogel H, Thornburg J and West B: A prospective study of early pregnancy loss in humans. Fertil Steril 86: 373-379, 2006.

3. Sierra S and Stephenson M: Genetics of recurrent pregnancy loss. Semin Reprod Med 24: 17-24, 2006.

4. Hyde KJ and Schust DJ: Genetic considerations in recurrent pregnancy loss. Cold Spring Harb Perspect Med 5: a023119, 2015.

5. Burks DJ, Font de Mora J, Schubert M, Withers DJ, Myers MG, Towery HH, Altamuro SL, Flint CL and White MF: IRS-2 pathways integrate female reproduction and energy homeostasis. Nature 407: 377-382, 2000

6. Lydon JP, DeMayo FJ, Funk CR, Mani SK, Hughes AR, Montgomery CA Jr, Shyamala G, Conneely OM and O'Malley BW: Mice lacking progesterone receptor exhibit pleiotropic reproductive abnormalities. Genes Dev 9: 2266-2278, 1995.

7. Nilsson EE and Skinner MK: Bone morphogenetic protein-4 acts as an ovarian follicle survival factor and promotes primordial follicle development. Biol Reprod 69: 1265-1272, 2003.

8. Ying Y and Zhao GQ: Cooperation of endoderm-derived BMP2 and extraembryonic ectoderm-derived BMP4 in primordial germ cell generation in the mouse. Dev Biol 232: 484-492, 2001.

9. Miyazono K, Kamiya Y and Morikawa M: Bone morphogenetic protein receptors and signal transduction. J Biochem 147: 35-51, 2010.

10. Derynck $R$ and Zhang YE: Smad-dependent and Smad-independent pathways in TGF-beta family signalling. Nature 425: 577-584, 2003.

11. van den Wijngaard A, Weghuis DO, Boersma CJ, van Zoelen EJ, Geurts van Kessel A and Olijve W: Fine mapping of the human bone morphogenetic protein-4 gene (BMP4) to chromosome 14q22-q23 by in situ hybridization. Genomics 27: 559-560, 1995.

12. Bakrania P, Efthymiou M, Klein JC, Salt A, Bunyan DJ, Wyatt A, Ponting CP, Martin A, Williams S, Lindley V, et al: Mutations in BMP4 cause eye, brain, and digit developmental anomalies: Overlap between the BMP4 and hedgehog signaling pathways. Am J Hum Genet 82: 304-319, 2008.

13. Oida S, Iimura T, Maruoka Y, Takeda K and Sasaki S: Cloning and sequence of bone morphogenetic protein 4 (BMP-4) from a human placental cDNA library. DNA Seq 5: 273-275, 1995.

14. Taulaviciute G, Cesaityte K, Joksas A and Serapiniene A: Genetic causes of recurrent miscarriages. Biomedicina 26: 61-64, 2016.

15. Suzuki S, Marazita ML, Cooper ME, Miwa N, Hing A, Jugessur A, Natsume N, Shimozato K, Ohbayashi N, Suzuki Y, et al: Mutations in BMP4 are associated with subepithelial, microform, and overt cleft lip. Am J Hum Genet 84: 406-411, 2009.

16. Lawson KA, Dunn NR, Roelen BA, Zeinstra LM, Davis AM, Wright CV, Korving JP and Hogan BL: Bmp4 is required for the generation of primordial germ cells in the mouse embryo. Genes Dev 13: 424-436, 1999.

17. Galloway SM, McNatty KP, Cambridge LM, Laitinen MP, Juengel JL, Jokiranta TS, McLaren RJ, Luiro K, Dodds KG, Montgomery GW, et al: Mutations in an oocyte-derived growth factor gene (BMP15) cause increased ovulation rate and infertility in a dosage-sensitive manner. Nat Genet 25: 279-283, 2000. 